these procedures were combined with Roux-en-Y anastomosis to protect the stomach from the effects of biliary reflux (Capper et al., 1967). In the two remaining cases vagotomy and pyloroplasty was done because of the extremely poor condition of the patient, and the larger erosions were undersewn. Both these patients continued to bleed. One required further more radical surgery and the other died.

\section{Relation to Drugs}

The cases under investigation could be divided into two groups according to whether or not the bleeding was preceded by the ingestion of drugs. Table $\mathrm{V}$ shows the incidence of drug-induced and idiopathic bleeding.

TABLE V.-Incidence of Drug-induced and Idiopathic Bleeding

\begin{tabular}{|c|c|c|c|c|c|c|}
\hline \multicolumn{4}{|c|}{ Bleeding } & \multirow{2}{*}{$\begin{array}{c}\text { Male } \\
8 \\
13\end{array}$} & \multirow{2}{*}{$\begin{array}{c}\text { Female } \\
7 \\
12\end{array}$} & \multirow{2}{*}{$\begin{array}{c}\text { Total } \\
\begin{array}{c}15 \\
25\end{array}\end{array}$} \\
\hline $\begin{array}{l}\text { Idiopathic } \\
\text { Drug-induced }\end{array}$ & 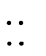 & 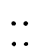 & 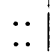 & & & \\
\hline Total . & $\ldots$ & $\ldots$ & .. & 21 & 19 & 40 \\
\hline
\end{tabular}

Twenty-five cases were thought to be drug-induced. The drugs implicated were aspirin (12 cases), alcohol (6 cases), butazolidin ( 5 cases), and steroids ( 2 cases). All four patients who died had drug-induced bleeding. This poses a problem in management. Bleeding which was drug-induced appeared to persist longer than idiopathic bleeding, making operation seem advisable; yet, retrospectively, this carries a higher mortality. On balance it seems that operation should be withheld if possible.

\section{Gastric Secretion}

In all patients who were subjected to operation the opened stomach was tested for acid with Universal indicator paper, and achlorhydria was found. Similarly, three cases were tested for acid by passing a gastric tube after the bleeding had stopped. Achlorhydria was found in each case.
Gastroscopic and naked-eye appearances at operation showed globular mucus, a known accompaniment of hypochlorhydria and achlorhydria.

Davenport (1964) showed that the mucosal barrier to hydrogen ions can be disrupted by various insults, of which aspirin is one (Lynch et al., 1964 ; Croft and Wood, 1967 ; Parry and Wood, 1967). Our findings would support this theory, and, as erosive gastritis is probably not an autoimmune phenomenon, this state is likely to be reversible when the insult is removed. The achlorhydria that we found is probably due not to increased acid production but to reabsorption of the hydrogen ions from the gastric lumen. However, Køster et al. (1955) reported their finding of an increased incidence of blood group $\mathbf{A}$ in association with hypochlorhydria.

The recovery of acid production after an episode of haemorrhagic erosive gastritis remains to be studied in a further series, but the likelihood of its recovery is the reason for the nature of the surgical treatment which we recommend.

Our thanks are due to Dr. R. J. Sandry and members of his staff for facilities made available in the laboratory ; to Miss E. H. L. Duncan, of the University of Bristol, for statistical help ; and to Dr. J. M. Naish for assistance with the preparation of this paper.

\section{REFERENCES}

Butler, T. J. (1967). Brit. med. F., 1, 360.

Capper, W. M., and Buckler, K. G. (1964). Brit. Y. Surg., 51, 752.

Capper, W. M., Butler, T. J., and Kilby, J. O. (1967). Gut, 8, 612. Carruthers, R. K., Giles, G. R., Clark, C. G., and Goligher, J. C. (1967). Brit. med.. ., 1,80 .

Coghill, N. F., Doniach, D., Roitt, I. M., Mollin, D. L., and Williams, A. W. (1965). Gut, 6, 48 .

Croft, D. N., and Wood, P. H. N. (1967). Brit. med. F., 1, 137.

Davenport, H. W. (1964). Gastroenterology, 46, 245

Horwich, L., Evans, D. A. P., McConnell, R. B., and Donohoe, W. T. A. (1966). Gut, 7, 680 .

Jones, F. A. (1961). In R. Maingot's Abdominal Operations, 4th ed., Jones, F. A. (1961). In

Køster, K. H., Sindrup, E., and Seele, V. (1955). Lancet, 2, 52.

Langmann, M. J. S., Hansky, J. H., Drury, R. A. B., and Jones, F. A. (1964). Gut, 5, 550 .

Lynch, A., Shaw, H., and Milton, G. W. (1964). Gut, 5, 230

Mackay, I. R. (1964). Gut, 5, 23.

Parry, D. J., and Wood, P. H. N. (1967). Gut, 8, 301.

\title{
Resistance to Suppression by Dexamethasone of Plasma 11-O.H.C.S. Levels in Severe Depressive Illness
}

\author{
B. J. CARROLL,* M.B., B.S., B.SC. ; F. I. R. MARTIN, $\dagger$ M.D., F.R.A.C.P. \\ BRIAN DAVIES, $\ddagger$ M.D., M.R.C.P., D.P.M., D.C.H., M.A.N.Z.C.P.
}

Brit. med. F., 1968, 3, 285-287

\begin{abstract}
Summary : Use of the midnight dexamethasone suppression test showed that the plasma 11-hydroxycorticosteroid (11-O.H.C.S.) level did not undergo its normal reduction in 14 out of 27 patients with severe depression. Resistance to dexamethasone suppression correlated with the clinical rating of the severity of depression, while recovery from depression was associated with return of normal responsiveness to dexamethasone. The explanation of these findings is unknown.
\end{abstract}

\footnotetext{
* Medical Research Fellow, Department of Psychiatry, University of Melbourne.

† Endocrinologist, the Royal Melbourne Hospital.

$\ddagger$ Cato Professor of Psychiatry, University of Melbourne, Clinical Sciences Building, Royal Melbourne Hospital, Victoria, Australia.
}

Evidence suggestive of increased adrenocortical activity in depression has been widely reported and recently reviewed by Fawcett and Bunney (1967) and Coppen (1967). The midnight dexamethasone suppression test has been extensively used in the assessment of patients with clinical evidence of adrenocortical overactivity to define normal feedback control (Nugent et al., 1965 ; McHardy-Young et al., 1967). We report our experience with this test in the assessment of adrenocortical function in patients with severe depressive illness.

\section{Subjects and Methods}

Twenty-seven patients with severe depressive illness admitted consecutively to the professorial psychiatric unit were studied. 
These were all typical melancholic patients with agitation, retardation, and delusional and suicidal thoughts as well as disturbance of sleep, appetite, and bowel function. There were 13 men and 14 women. Their ages ranged from 25 to 82, with a mean of 59 years. Sixteen had a past history of similar depressive episodes. The average length of severe symptoms before admission was five weeks. No patient had had electric convulsion therapy (E.C.T.) for at least a month before admission, and the investigations were not started until patients had been free of all drugs (except amylobarbitone) for one week. Those with clinical evidence of cardiovascular or endocrine disease were excluded.

On the patients' admission clinical ratings were made of the depressed mood, agitation, anxiety, retardation, anorexia, difficulty in concentrating, fatigue, and tiredness on a fivepoint scale $(0=$ none, $4=$ severe). Subsequently, of the 27 patients 17 received a course of E.C.T., 7 received antidepressant drugs, and 3 improved spontaneously.

For comparison, 22 others admitted to the same psychiatric wards over the same period were also studied. They included patients with schizophrenia, personality disorders, severe anxiety, and alcoholism. None of them had significant depressive symptoms. Their ages ranged from 18 to 59 , with a mean of 38 years. These patients received amylobarbitone only in the period between admission and testing. The amount given was similar to that received by the depressives.

Tests were repeated on 14 of the depressed patients when they had recovered just before their discharge from hospital. These 14 were having no drugs other than amylobarbitone at the time of retesting, apart from one who was treated with imipramine.

All patients received the same general nursing and medical care, and all were given a normal ward diet.

Blood for plasma 11-O.H.C.S. estimations was collected in tubes containing 15 units of lithium heparin per $10 \mathrm{ml}$. of blood. Samples were collected at 8.30 a.m. and 4.30 p.m. Dexamethasone phosphate $2 \mathrm{mg}$. was given orally at midnight, and a further plasma 11-O.H.C.S. sample was taken at 8.30 a.m. the next day. Plasma 11-O.H.C.S. determinations were measured by the fluorometric technique of Mattingly (1962) by means of a CGA spectrophotofluorometer (model DC/3000).

\section{Results}

Diurnal plasma 11-O.H.C.S. levels (means and S.D.) are shown in Table I. There were no differences in the 8.30 a.m. levels in the three groups of patients, and all groups show a diurnal variation. The recovered depressives had a significantly lower level at 4.30 p.m. $(t=3.12, \mathrm{P}<0.01)$ compared with their own levels on admission.

\begin{tabular}{|c|c|c|c|c|}
\hline & & $\begin{array}{c}\text { Depressed } \\
\text { Patients (27) }\end{array}$ & $\begin{array}{c}\text { Recovered } \\
\text { Depressives (14) }\end{array}$ & $\begin{array}{l}\text { Non-depressed } \\
\text { Patients (22) }\end{array}$ \\
\hline $\begin{array}{l}8.30 \text { a.m. } \\
4.30 \text { p.m. }\end{array}$ & $\ldots$ & $\begin{array}{l}21 \cdot 3(\text { S.D. } 7 \cdot 0) \\
15 \cdot 1 \text { (S.D. 6.6) }\end{array}$ & $\begin{array}{r}18.6 \text { (S.D. } 5 \cdot 7 \text { ) } \\
9.4 \text { (S.D. } 4 \cdot 9 \text { ) }\end{array}$ & $\begin{array}{l}21.6 \text { (S.D. } 7 \cdot 5 \text { ) } \\
13 \cdot 4 \text { (S.D. } 6 \cdot 0 \text { ) }\end{array}$ \\
\hline
\end{tabular}

The 11-O.H.C.S. levels ( $\mu$ g. $/ 100 \mathrm{ml}$ ) at 8.30 a.m. after a midnight dose of $2 \mathrm{mg}$. dexamethasone phosphate were: 13.1 (S.D. 7.0) in the 27 depressed patients, 5.3 (S.D. 5.1) in the 14 recovered depressives, and 4.8 (S.D. 3.7) in 22 nondepressed patients. The difference between the non-depressed and depressed patients is significant at the 0.001 level $(t=3.36)$.

Individual levels after dexamethasone are shown in the Chart. It will be seen that, while most of the non-depressed and all but one of the recovered depressives suppressed below a level of $10 \mu \mathrm{g} . / 100 \mathrm{ml}$., only half of the depressives did so. Of the 14 patients on whom tests were repeated eight had failed to suppress normally on admission, while only one was dexa- methasone-resistant on recovery after E.C.T. Three of the non-depressed patients also failed to suppress normally. In two the diagnosis was personality disorder, while the third had an hysterical amnesia.

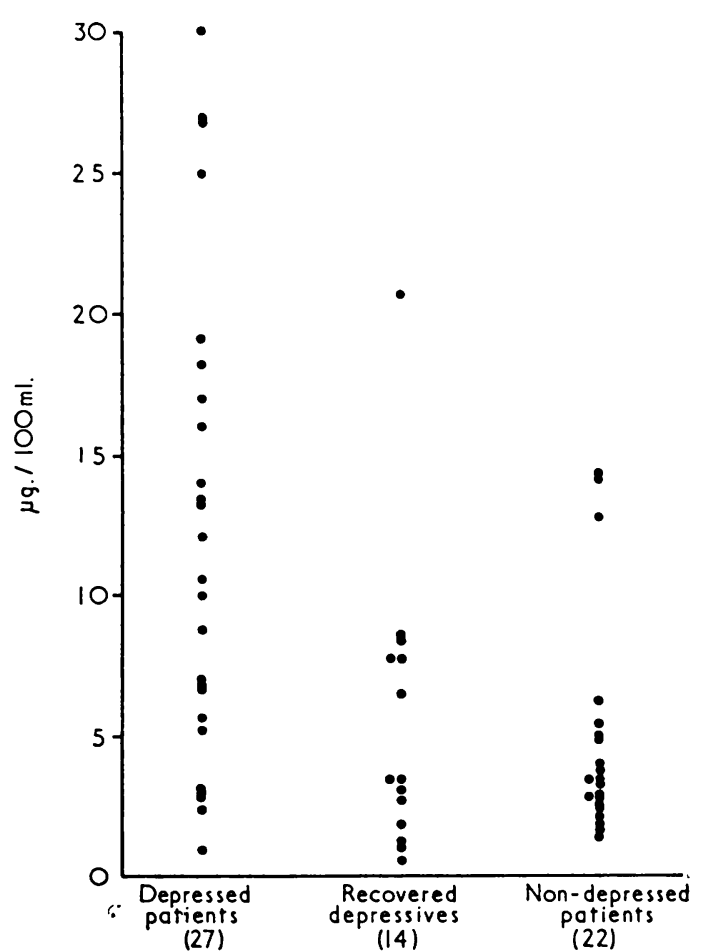

Individual 11-O.H.C.S. levels ( $\mu \mathrm{g} . / 100 \mathrm{ml}$.) after $2 \mathrm{mg}$. dexamethasone phosphate.

These figures show that half of the patients admitted to hospital with severe depressive illness are resistant to dexamethasone suppression, but on recovery this abnormality was found in only one patient.

Table II shows a $\chi^{2}$ distribution of the depressed patients above and below the median values in respect to the total scores on the clinical rating scale and the post-dexamethasone 11-O.H.C.S. This distribution indicates a significant relation between the clinical rating of severity of depression and the resistance of plasma 11-O.H.C.S. to suppression by dexamethasone.

\begin{tabular}{|c|c|c|c|c|c|}
\hline \multicolumn{4}{|c|}{ Severity of Symptoms } & \multirow{2}{*}{ 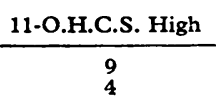 } & 11-O.H.C.S. Low \\
\hline $\begin{array}{l}\text { High } \\
\text { Low }\end{array}$ & $\because$ & . & 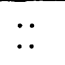 & & $\begin{array}{r}3 \\
11\end{array}$ \\
\hline
\end{tabular}

The age, sex, length of time of symptoms before admission, and severity of individual symptoms did not correlate with dexamethasone resistance.

\section{Discussion}

These results show that the midnight dexamethasone suppression test discriminates between two groups of patients (depressed and non-depressed) who have identical basal morning and evening plasma 11-O.H.C.S. levels. This approach highlights the inadequacy of single estimations of plasma levels of 11-O.H.C.S. as an index of pituitary-adrenal function.

- Fawcett and Bunney (1967) mention that some of their severe depressives failed to suppress normally with dexamethasone, though Gibbons (1966) has stated that with use of an infusion method the plasma 11-O.H.C.S. levels in depressives decline at the same rate as plasma levels of healthy controls. 
The reason that some severely depressed patients do not achieve suppression of plasma 11-O.H.C.S. after dexamethasone is uncertain. It is possible that adrenocortical activity has become relatively autonomous in these patients, similar to the situation in Cushing's syndrome. However, the reversible nature of the defect in most patients, the absence of any clinical features of Cushing's syndrome, and the preservation of a normal diurnal rhythm make this unlikely. Other possibilities are that dexamethasone fails to reach the hypothalamus in the resistant patients or that the steroid-sensitive neurones are subjected to an abnormal drive from other limbic areas.

The conflicting reports that deal with levels of blood 11-O.H.C.S. and their relation to depression have been reviewed by Coppen (1967). Our own findings are similar to those reported by Brooksbank and Coppen (1967)-namely, that morning levels of 11-O.H.C.S. are within the normal range, and that the diurnal variation is not affected. We found a significant fall in the 4.30 p.m. 11-O.H.C.S. levels in the recovered depressed group, but we did not test the non-depressed patients after a similar time in hospital, because they had received a variety of drugs during treatment.

We have eliminated interfering drug effects so far as is possible. No patient received any drug except amylobarbitone for at least a week before and during testing (apart from one recovered depressive who was also having imipramine). As a group the depressives needed larger amounts of amylobarbitone during the initial testing period than they did before discharge. Barbiturates have been shown to interfere with the release of A.C.T.H. (Krieger and Krieger, 1967), but there is no evidence that they can enhance A.C.T.H. release. We have also found that neither amylobarbitone nor imipramine interferes with the estimation of plasma 11-O.H.C.S. by fluorescence (Carroll, 1968).

The results presented here show that the failure of plasma 11-O.H.C.S. to suppress with dexamethasone may not be diagnostic of adrenocortical hyperplasia if the patient is severely depressed. They also indicate the need for further definition of hypothalamic-pituitary function in depressive illness.

It is a pleasure to thank Dr. Cameron Baird and Dr. Margot Baillie for generously providing facilities for one of us (B. J. C.) to perform the 11-O.H.C.S. determinations. We also thank Messrs. Geigy Pharmaceuticals for financial support.

\section{Addendum}

Since preparing this paper we have considered another possible explanation for our results. Doig et al. (1966) reported that 7 out of 12 depressives showed a plasma 11-O.H.C.S. peak at 3 a.m. instead of at 6 a.m. as in normal people. They suggested that the diurnal curve of plasma 11-O.H.C.S. was shifted "to the left" in these patients. On recovery normal 6 a.m. peaking was found.

On consideration of these data we felt that the midnight dose of dexamethasone may have been given too late in the cycle to affect the diurnal rise in our depressives. We have now compared the effects of dexamethasone given at 9 p.m. and at midnight on four further patients. The results are shown in Table III. Normal suppression clearly failed to occur on both occasions. These figures indicate that the failure of the depressed patients to suppress their plasma 11-O.H.C.S. levels is not simply a function of the timing of dexamethasone administration in relation to an altered diurnal rhythm.

TABLE III

\begin{tabular}{|c|c|c|c|c|}
\hline \multirow{2}{*}{$\begin{array}{l}\text { Case } \\
\text { No. }\end{array}$} & \multicolumn{2}{|c|}{$\begin{array}{c}\text { Basal Plasma 11-O.H.C.S. } \\
(\mu \mathrm{g} . / 100 \mathrm{ml} .) \\
\end{array}$} & \multicolumn{2}{|c|}{$\begin{array}{l}\text { Plasma 11-O.H.C.S. at } 8.30 \mathrm{a.m} \text {. } \\
\text { after Dexamethasone } 2 \mathrm{mg} \text {. at: }\end{array}$} \\
\hline & 8.30 a.m. & 4.30 p.m. & 9 p.m. & 12 Midnight \\
\hline $\begin{array}{l}1 \\
2 \\
3 \\
4\end{array}$ & $\begin{array}{l}35 \\
20 \\
28 \cdot 2 \\
28 \cdot 6\end{array}$ & $\begin{array}{l}23 \cdot 7 \\
10 \cdot 4 \\
20 \cdot 1 \\
19 \cdot 5\end{array}$ & $\begin{array}{l}34 \cdot 6 \\
14 \cdot 6 \\
21 \\
22 \cdot 4\end{array}$ & $\begin{array}{l}35 \cdot 4 \\
19 \cdot 2 \\
27 \cdot 2 \\
17 \cdot 2\end{array}$ \\
\hline
\end{tabular}

\section{REFERENCES}

Brooksbank, B. W. L., and Coppen, A. (1967). Brit. F. Psychiat., 113, 395

Carroll, B. J. (1968). Unpublished observations.

Coppen, A. (1967). Brit. F. Psychiat., 113, 1237. oig, R. J., Mummery, R. V.

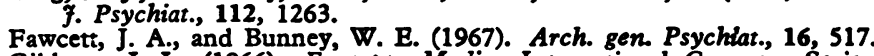
Gibbons, J. L. (1966). Excerpta Medica International Congress Series, No. 111, Abstract No. 370. Amsterdam.

Krieger, D. T., and Krieger, H. P. (1967). Science, 155, 1421.

McHardy-Young, S., Harris, P. W. R., Lessoff, M. H., and Lyne, C. (1967). Brit. med. Ұ., 2, 740.

Mattingly, D. (1962). F. clin. Path., 15, 374.

Nugent, C. A., Nichols, T., and Tyler, F. H. (1965). Arch. intern. Med., 116, 172 .

\title{
Viral Antibody Levels and Clinical Status in Acute Exacerbations of Chronic Bronchitis: a Controlled Prospective Study*
}

\author{
A. C. STENHOUSE, † B.MED.SC., M.B., M.R.C.P., M.R.A.C.P.
}

Brit. med. F., 1968, 3, 287-290

Cummary : A controlled prospective study was made of a group of patients with chronic bronchitis, in which serum antibodies against a group of viruses and Mycoplasma pneumoniae were estimated at regular intervals. Sixteen significant rises in antibody titre were shown, of which eight were associated with clinical acute exacerbations of bronchitis. In individual patients no correlation was found between the number of acute

* This study is included in material to be presented in a thesis as partial fulfilment of the M.D. degree of the University of Otago, New Zulfilment.

tWellcome Research Fellow, University Department of Medicine, the Royal Hospital, Sheffield, and the University of Sheffield Virus Research Laboratory, Lodge Moor Hospital, Sheffield. Address from 21 September: London School of Hygiene and Tropical Medicine, Keppel Street, London W.C.1. exacerbations or the aetiological agent and persistent change in ventilatory function as expressed by the F.E.V.0.75

This study was compared with the results of a previous parallel investigation of the same patients done to study the significance of rhinovirus infections. In the present investigation $12 \%$ of the acute exacerbations were associated with the 11 agents tested compared with $14 \%$ associated with rhinoviruses in the earlier work.

\section{Introduction}

In healthy subjects the viruses isolated from common acute respiratory infections differ according to the age of the person 